\title{
EVALUATING APPROACHES RELATING ECOSYSTEM PRODUCTIVITY WITH DESIS SPECTRAL INFORMATION
}

\author{
K.F. Huemmrich ${ }^{1}$, P.E.K. Campbell ${ }^{1}$, D.J. Harding ${ }^{2}$, K.J. Ranson ${ }^{2}$, R. Wynne ${ }^{3}$, V. Thomas ${ }^{3}$, E.M. Middleton ${ }^{2}$ \\ ${ }^{1}$ Joint Center for Earth Systems Technology, University of Maryland Baltimore County, Baltimore, MD 21228, USA - (huemmric, \\ petya)@umbc.edu \\ ${ }^{2}$ NASA Goddard Space Flight Center, Greenbelt, MD 20771, USA - (david.j.harding, kenneth.j.ranson, \\ elizabeth.m.middleton)@nasa.gov \\ ${ }^{3}$ Department of Forest Resources and Environmental Conservation, Virginia Polytechnic Institute and State University, Blacksburg, \\ VA 24061, USA - (wynne, thomasv)@vt.edu
}

KEY WORDS: Gross Primary Productivity (GPP), Hyperspectral, Spectral Vegetation Indices, Forests, Eddy Covariance, Photochemical Reflectance Index (PRI).

\begin{abstract}
:
Data from the DLR Earth Sensing Imaging Spectrometer (DESIS), mounted on the International Space Station (ISS), were used to develop and test algorithms for remotely retrieving ecosystem productivity. Twenty DESIS images were used from three widely separated forested study sites representing deciduous and conifer forests. Gross primary production (GPP) values from eddy covariance flux towers at the sites were matched with DESIS spectral reflectances collected on the same days. Multiple algorithms were successful relating spectral reflectance with GPP, including: spectral vegetation indices (SVI) sensitive to chlorophyll content, SVI used in a photosynthetic light-use efficiency model framework, spectral shape characteristics through spectral derivatives and absorption feature analysis, and statistical models leading to multiband hyperspectral indices from partial least squares regression. Successful algorithms were able to achieve $\mathrm{R}^{2}$ better than 0.7 using a diverse set of observations combining data from different sites from multiple years and at multiple times during the year. The demonstrated robustness of the algorithms provides some confidence in using DESIS imagery to map spatial patterns of GPP.
\end{abstract}

\section{INTRODUCTION}

Forests provide important ecological and economic services including climate change mitigation by removing $\mathrm{CO}_{2}$ from the atmosphere through photosynthesis and storing carbon in biomass and soils. However, climate change and anthropogenic activities have significantly affected forest ecosystem function and productivity by imposing novel combinations of multiple stresses which act to alter plant biochemistry and traits. The challenge to forest management is to balance and enhance the economic and environmental values of forests in this changing environment. Remote sensing has the potential to provide critical actionable information for forest managers.

The physiological condition of leaves is related to the contents of photosynthetic and photoprotective leaf pigments which can be inferred from spectral reflectance and are related to forest productivity. Ideally approaches using the spectral information should be seamlessly applicable at different times of year and across different locations and forest types. Successful approaches must be both sensitive to changes in productivity and insensitive to confounding factors, such as forest type, background reflectance, and shadowing. Thus, we wish to test these approaches across multiple sites and at different times of the year and across multiple years.

In this study spectral reflectance observations from DLR Earth Sensing Imaging Spectrometer (DESIS) are used to examine approaches to use spectral information to determine ecosystem gross primary productivity (GPP). Spaceborne imagers, such as DESIS, have the capability to routinely and repeatably collect observations from widely distributed sites, thus making them important tools for the evaluation of the ability for candidate algorithms to be widely applied. Further, the hyperspectral imagery from DESIS provides the opportunity to examine approaches that use spectral information not available from multiband instruments such as Landsat Enhanced Thematic Mapper + $(\mathrm{ETM}+)$, Operational Land Imager $(\mathrm{OLI})$, Moderate resolution Imaging Spectrometer (MODIS), or Visible Infrared Imaging Radiometer Suite (VIIRS).

\section{METHODS}

\subsection{Site Descriptions}

DESIS images were collected for three widely separated forested sites in the continental United States. These sites were the National Ecological Observatory Network (NEON) Wind River Experimental Forest (US-xWR), the NEON University of Notre Dame Environmental Research Center (US-xUN), and the Harvard Forest (US-Ha1) flux tower site.

The NEON Wind River Experimental Forest site is located in the Pacific Northwest, in state of Washington, USA $\left(45.8205^{\circ} \mathrm{N}\right.$, $\left.121.9519^{\circ} \mathrm{W}\right)$. The site is dominated by evergreen needleleaf forests, predominately Douglas fir (Pseudotsuga menziesii) and western hemlock (Tsuga heterophylla). The Wind River site is characterized by warm dry summers and cool wet winters (https://www.neonscience.org/field-sites/wref).

The NEON University of Notre Dame Environmental Research Center is primarily second-growth mixed forest dominated by red and sugar maple (Acer rubrum and A. saccharum), aspen (Populus tremuloides), and birch (Betula papyrifera). The site is located near the border of Michigan's Upper Peninsula and northern Wisconsin, USA $\left(46.2339^{\circ} \mathrm{N}, 89.5373^{\circ} \mathrm{W}\right)$. The climate has very cold winters and cool summers with occasional 
hot periods. Most precipitation falls during the warmer months (https://www.neonscience.org/field-sites/unde).

The Harvard Forest site is located in central Massachusetts USA $\left(42.5378^{\circ} \mathrm{N}, 72.1715^{\circ} \mathrm{W}\right)$. The area has hot, humid summers and cold, snowy winters. The site is dominated by red oak (Quercus rubra) and red maple (Acer rubrum) (Urbanski et al. 2007).

\subsection{Productivity Measurements}

All of the study sites have operating flux towers where $\mathrm{CO}_{2}$, water, and energy fluxes are measured using eddy covariance methods. The measured net ecosystem production (NEP) was partitioned into GPP and ecosystem respiration (Re). Relationships between nighttime NEP, when there is no photosynthetic GPP component to the $\mathrm{CO}_{2}$ flux, and air temperature were developed and used to calculate Re to derive GPP during the day (Amiro et al. 2006, Reichstein et al. 2005).

Half hourly GPP values between 10:00 AM and 2:00 PM local time were averaged together to produce a midday GPP average values (Fig. 1). US-xWR, being an evergreen forest site, is productive all through the year, although with generally higher production during the summer. The two deciduous sites, USxUN and US-Ha1, have strong seasonal variability in GPP, from winter with no production then a rapid springtime increase to a midsummer high production followed by an autumn drop back down (Fig.1)

\subsection{DESIS Spectral Data}

DESIS images were downloaded from the Teledyne Brown Engineering Geospatial Solutions data distribution system (TCloud, https://teledyne.tcloudhost.com/) as surface reflectances (L2A product). These DESIS data cover the spectral range from 400 to $1000 \mathrm{~nm}$ with $\sim 2.5 \mathrm{~nm}$ spectral sampling and a $30 \mathrm{~m}$ spatial resolution. Detailed descriptions of the DESIS data products are available in the DESIS Algorithms Theoretical Basis Document (DESIS ATBD, 2015).

Multiple DESIS images were acquired for each site, providing observations at different times through the year and growing season with US-xWR having 8 images, US-xUN with 6 images, and US-Ha1 also with 6 images. The timing of these observations in comparison to the seasonal cycle of GPP are shown in Fig. 1.

From each image, pixels within a region of interest (ROI) around the flux tower were extracted and averaged. The ROI covered an area representative of the footprint of the eddy covariance flux measurements with 25 pixels being averaged for US-xWR and 10 pixels averaged for both US-xUN and US-Ha1. Averaged spectral reflectances are shown in Fig. 2. Most spectra show the typical green plant reflectance shape, but in all of the sites there are wintertime observations with high visible reflectances indicating snow cover. The snow covered observations for US$\mathrm{xWR}$ are noteworthy as that forest continued to be productive at that time compared to the wintertime deciduous sites. The DESIS reflectances were matched with the midday GPP from the flux towers for the same day as the overpasses.

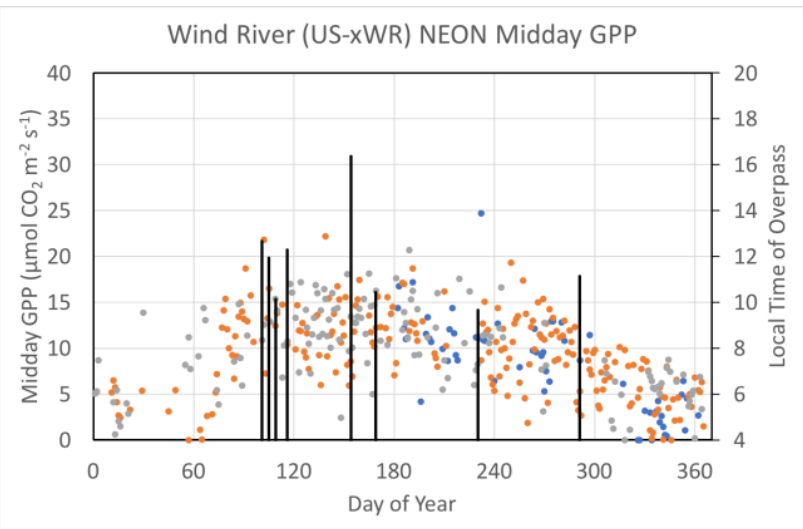

Notre Dame Env. Res. Cntr (US-xUN ) Midday GPP
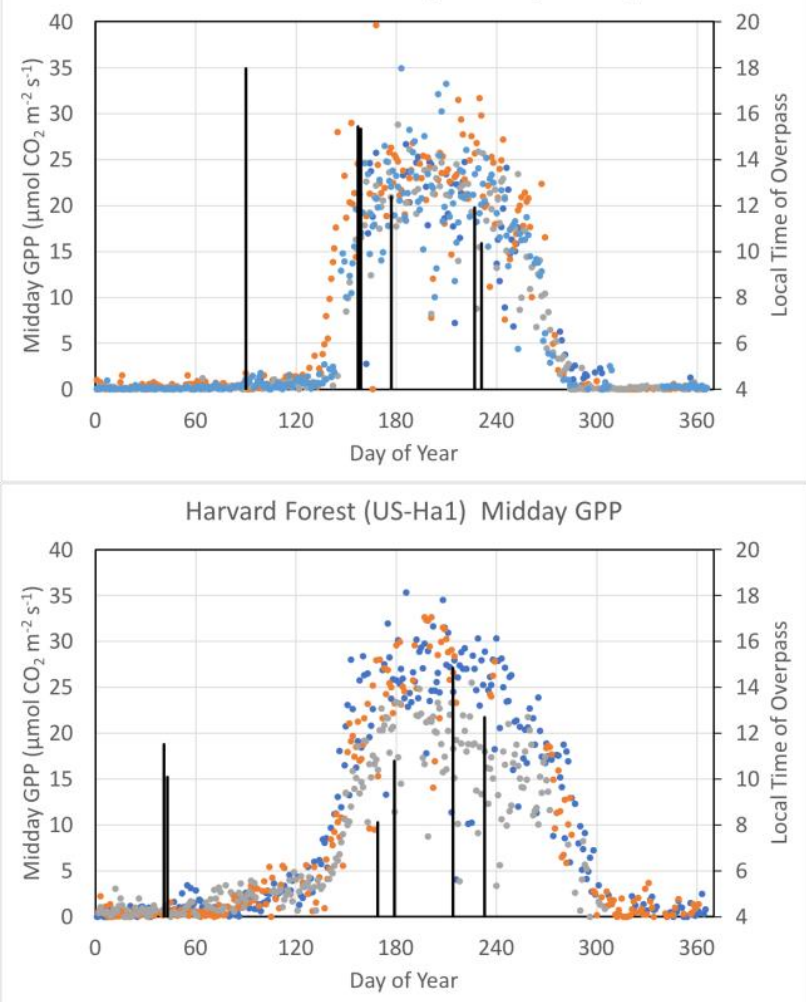

Figure 1. Seasonal patterns of midday average GPP for the three study sites, with blue points from 2018, orange points from 2019 and grey points from 2020. Vertical black lines indicate days of DESIS image collection. The height of these lines indicates the time of day of the overpass. Upper plot shows data for Wind River Experimental Forest (US-xWR), the middle plot has data for University of Notre Dame Environmental Research Center (US-xUN), and the bottom plot shows data for Harvard Forest (US-Ha1). 

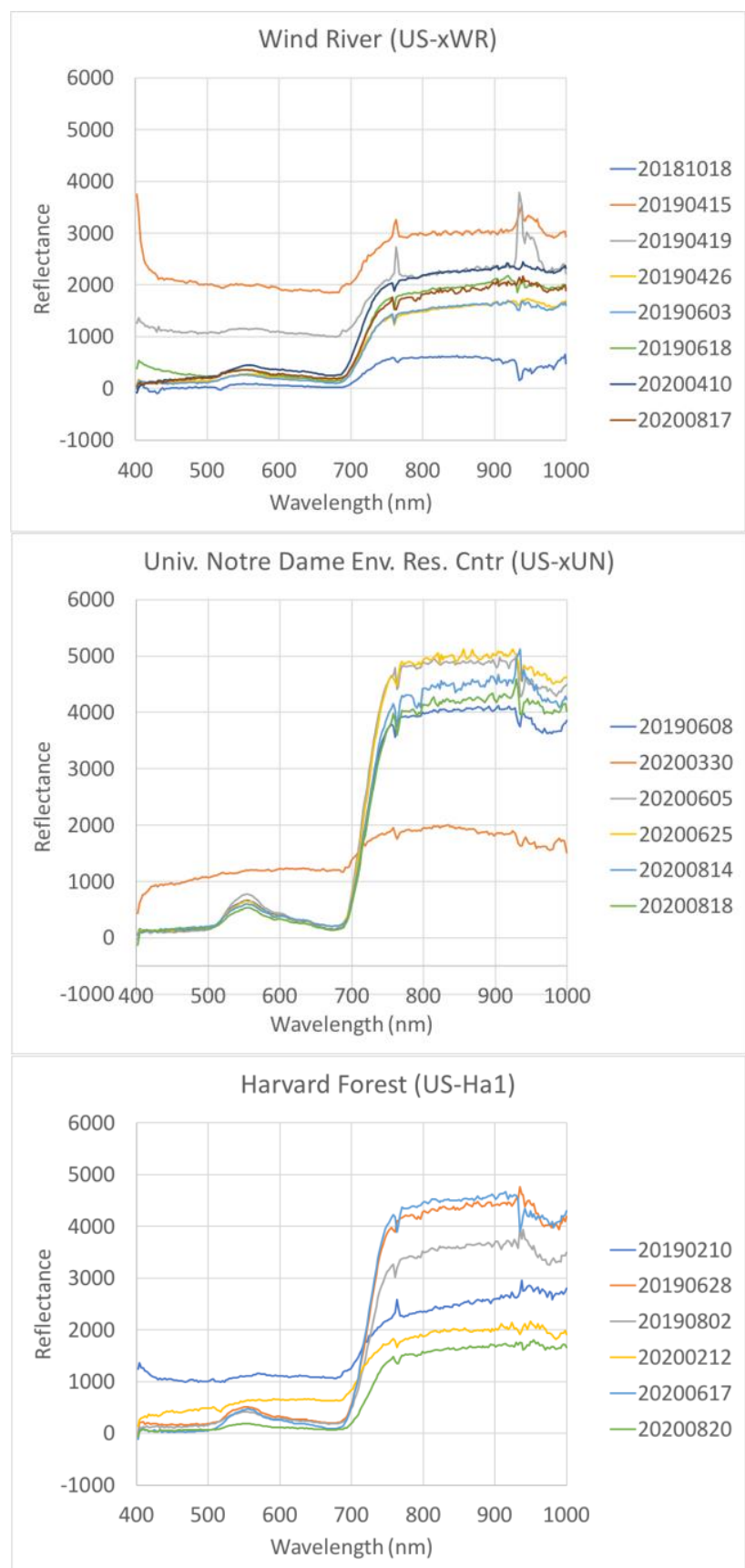

Figure 2. Average DESIS surface reflectance spectra for areas around flux towers. The y-axis units are reflectance $* 10^{4}$.

Observation dates are given in the legends in the format

YYYYMMDD. Upper plot shows data for Wind River

Experimental Forest (US-xWR), the middle plot has data for University of Notre Dame Environmental Research Center (US$\mathrm{xUN}$ ), and the bottom plot shows data for Harvard Forest (USHa1).

\subsection{Analysis Approaches}

Our objectives are to develop robust algorithms for estimating GPP using remotely sensed spectral information that can be applied to observations from multiple times of the day, different times in the growing season, and over different sites with different forest types. We evaluated multiple approaches testing how well various values calculated from the DESIS reflectance were related to the midday GPP based on the coefficient of determination $\left(\mathrm{R}^{2}\right)$ of linear regressions between the variables. Approaches included:

1) Spectral Vegetation Indices (SVI): SVI are algebraic combinations of a few spectral bands and are popular methods for using remotely sensed data to study vegetation. There are numerous SVI (Roberts et al. 2011), we focused on two approaches using SVI in this study.

One way to connect SVI with GPP is in the framework of the Light Use Efficiency (LUE) model. The basic form of the model is

$$
\mathrm{G}=\varepsilon \mathrm{fPAR} \text { Qin }=\varepsilon \text { APAR }
$$

where $\mathrm{G}$ is the GPP; Qin is the incoming photosynthetically active radiation (PAR), fPAR is the fraction of PAR absorbed by vegetation; APAR is the PAR absorbed by vegetation or the product of fPAR and Qin; and $\varepsilon$ is the photosynthetic light use efficiency (Monteith 1977, Russell et al. 1989). Here we consider the Normalized Difference Vegetation Index (NDVI)

$$
N D V I=\frac{\rho_{N I R}-\rho_{V i s}}{\rho_{N I R}+\rho_{V i s}}
$$

where the near infrared reflectance $\rho_{\text {NIR }}$ is the average reflectance of the bands between 798 and $804 \mathrm{~nm}$ and the visible reflectance $\rho_{\mathrm{V} \text { is }}$ is the average between 678 and $684 \mathrm{~nm}$, to be related to the fPAR term and $\varepsilon$ is related to the Photochemical Reflectance Index (PRI)

$$
P R I=\frac{\rho_{532}-\rho_{571}}{\rho_{532}+\rho_{571}}
$$

using the $532 \mathrm{~nm}$ and $571 \mathrm{~nm}$ reflectances (Huemmrich et al. 2017, Campbell et al. 2013, Grace et al. 2007).

A second approach uses an index sensitive to vegetation chlorophyll content $\left(\mathrm{C}_{\mathrm{i}}\right)$ based on the response of reflectances in the spectral red edge

$$
C_{i}=\frac{\rho_{791}}{\rho_{R E}}-1
$$

where $\rho R E$ is the reflectance of a band in the red edge spectral region (Ustin et al. 2009, Gitelson 2011). Chlorophyll content is related to photosynthetic capacity providing a link to GPP (Peng and Gitelson 2011).

2) Spectral Shape Descriptors: These approaches exploit the information available from hyperspectral data in the shape of the reflectance spectra. The spectral shape is affected by leaf pigments, such as chlorophyll absorption, and thus leaf biochemistry (Campbell et al. 2013, Huemmrich et al. 2017). Derivatives of reflectance spectra are a way of describing the spectral shape. They have also been shown to decrease the effects of background reflectance variations that may be a source of noise in many vegetation indices (Hall et al. 1990). Spectral first derivatives were calculated using five-point linear SavitzkyGolay filter (Savitzky and Golay 1964).

Pigment absorption features can also be described using a continuum removal technique where a continuum line is extended across the absorption feature and the continuumremoved reflectance is calculated by dividing the observed reflectance value by the reflectance level of the continuum line at the same wavelength. This normalizes reflectance allowing a comparison across a common baseline (Kokaly 2011). In this 
study we examine the continuum removed chlorophyll red absorption depth (Campbell et al. 2013).

3) Partial Least Squares Regression (PLSR) is a statistical approach that was developed to for cases with few samples and many predictor variables. It has been used in the remote sensing of vegetation pigments, biochemistry, and productivity using imaging spectrometer data from aircraft (Asner et al. 2015, Serbin et al. 2015) and satellites (Huemmrich et al. 2017, 2019).

\section{RESULTS}

\subsection{Spectral Vegetation Indices}

The relationship between NDVI and the midday GPP is shown in Fig. 3. The regression itself is driven by the large differences between the low wintertime and very high summertime values of the deciduous forest sites. The observations with snow cover all have low values of NDVI, which results in the US-xWR snow observations to be well off of the regression line. Further, NDVI provides no information on the variability in GPP among the summertime deciduous observations.

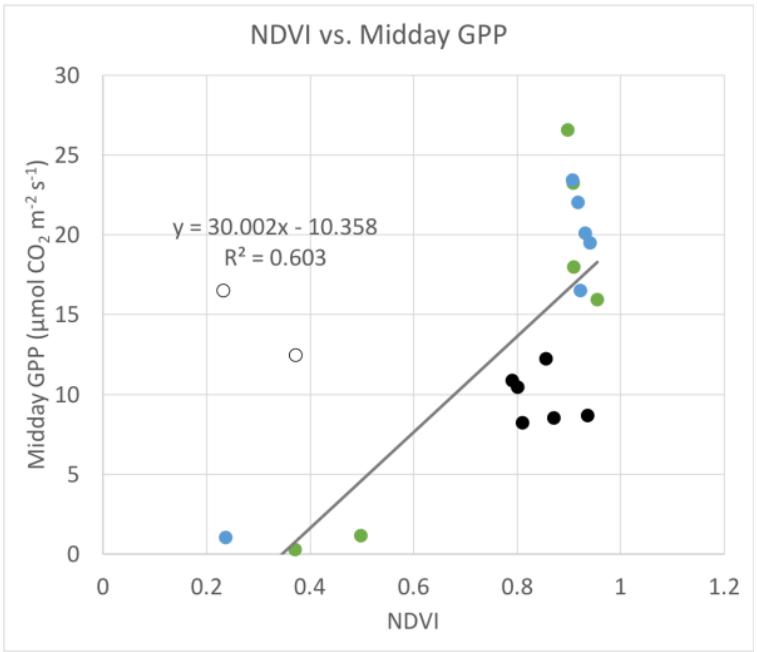

Figure 3. NDVI from DESIS compared with midday GPP from flux towers. Black points are for US-xWR with open white points being the US-xWR snow covered observations, blue points are for US-xUN, and green points are for US-Ha1 observations.

PRI, however, is able to separate out the variability in LUE that determines GPP for those summertime deciduous observations (Fig. 4).

The DESIS hyperspectral data provides an opportunity to evaluate the optimum placement of the red edge band in the Chlorophyll Index $\left(\mathrm{C}_{\mathrm{i}}\right)$ for retrieving GPP. All of the spectral bands between 702 and $758 \mathrm{~nm}$ were used as the red edge band in Eq. 4. Correlations with midday GPP were greater than 0.8 for all of the bands between 702 and $734 \mathrm{~nm}$, with the $716 \mathrm{~nm}$ band having the highest correlation ( $\mathrm{R}=0.88)$ (Fig. 5). Fig. 6 provides an example of the performance of $\mathrm{Ci}$ using the $705 \mathrm{~nm}$ band. Once again, the presence of snow strongly affects this vegetation index.

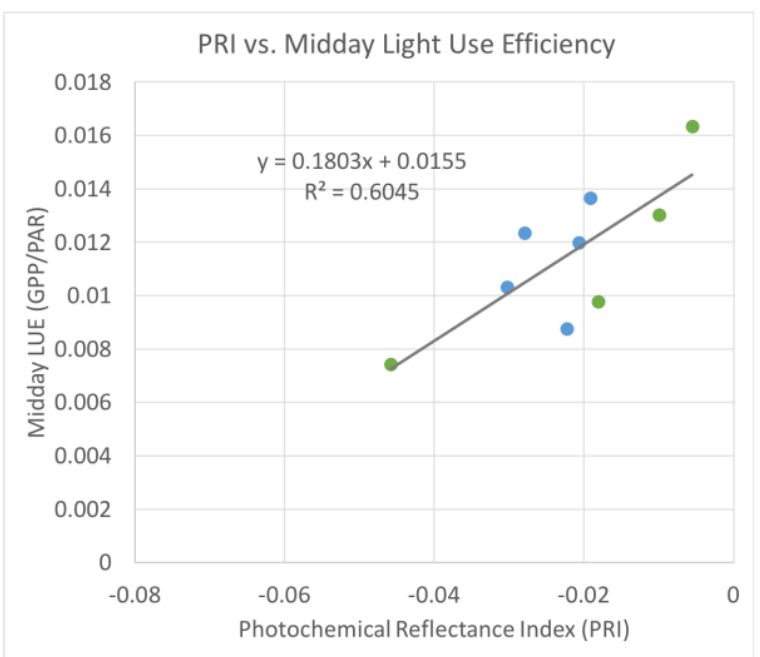

Figure 4. PRI from DESIS compared with midday photosynthetic light use efficiency (GPP/incident PAR) from flux towers for summertime deciduous site observations. Blue points are for US-xUN, and green points are for US-Ha1 observations.

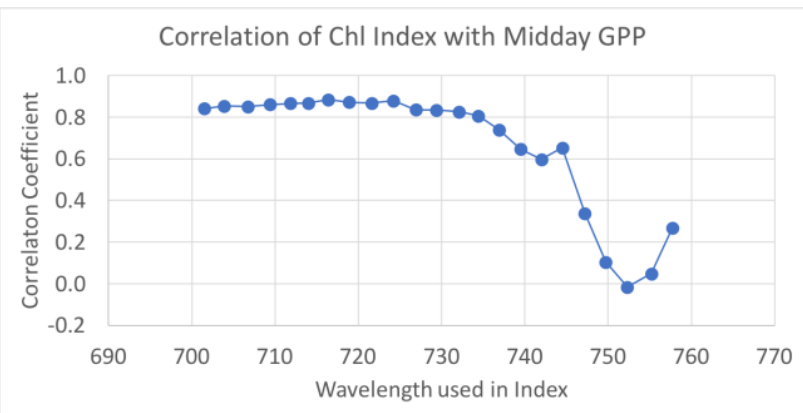

Figure 5. Correlation coefficients between midday GPP and the chlorophyll index $\left(\mathrm{C}_{\mathrm{i}}\right)$ using different wavelength bands for the red edge wavelength in Eq. 4.

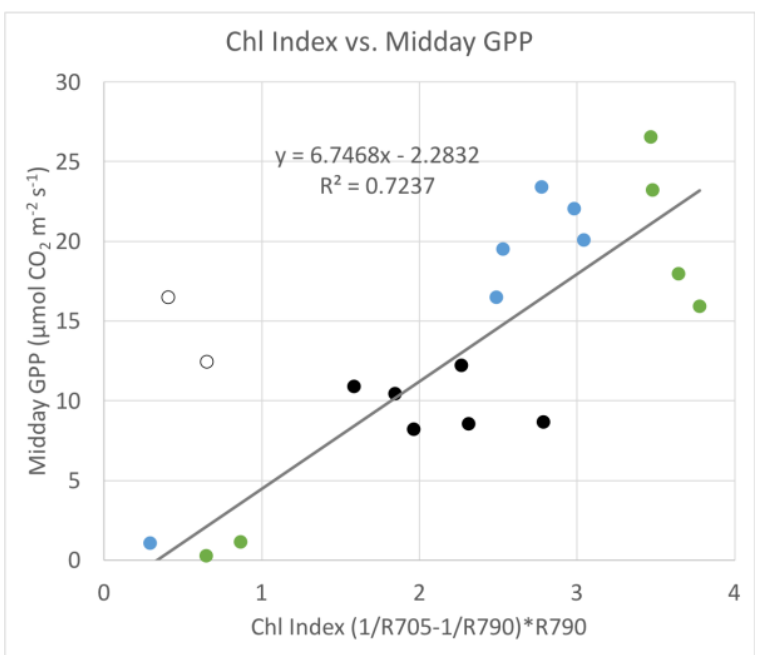

Figure 6. $\mathrm{C}_{\mathrm{i}}$ using the $705 \mathrm{~nm}$ red edge band from DESIS compared with midday GPP from flux towers. Point colors are described in Fig. 3 caption. 


\subsection{Spectral Shape Metrics}

The first derivatives across all of the wavelength bands were compared with the midday GPP allowing identification of spectral regions with high correlations. Bands with high correlations occurred along the red edge and on the flanks of the green peak (Fig. 7).

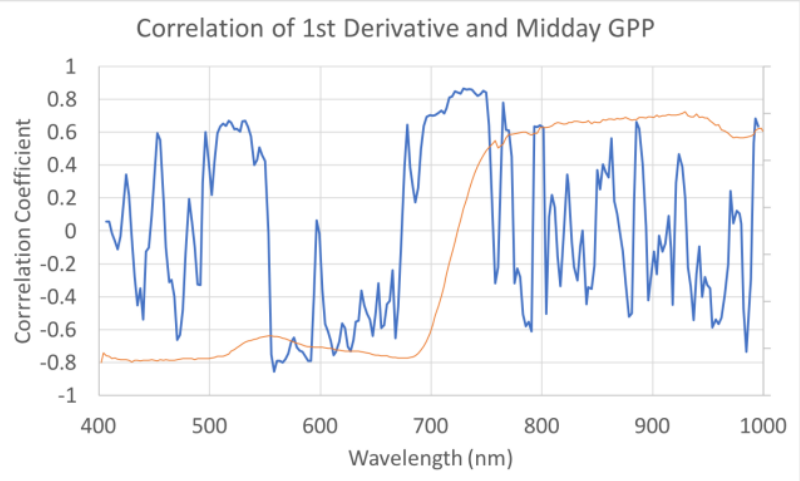

Figure 7. Correlations of the first derivative of the DESIS reflectance spectra compared with midday GPP from flux towers. Blue line shows the correlation values, orange line is a representative reflectance spectra (not scaled to y-axis) for orientation.

The best performing derivative wavelength was at $558 \mathrm{~nm}$ on the side of the green peak. Not only do these values describe midday GPP across the sites, but the US-xWR snow covered observations have low residuals from the regression line (Fig. 8).

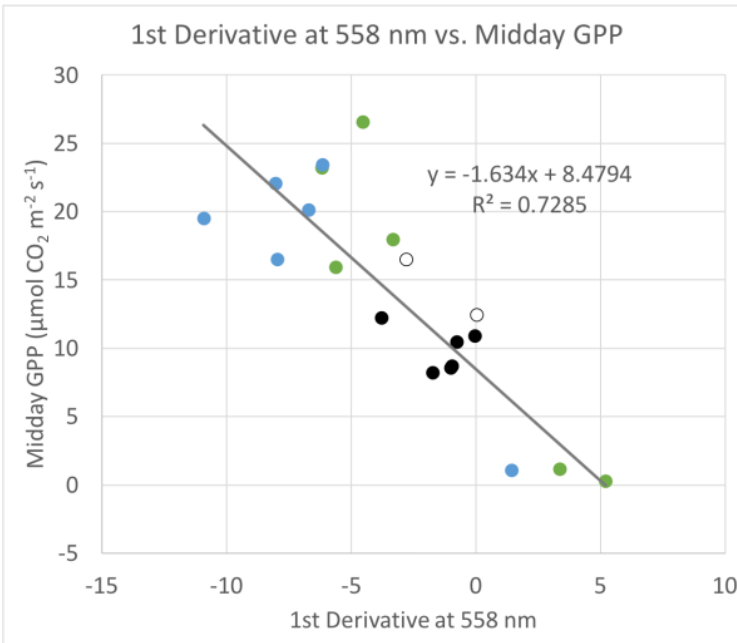

Figure 8. First derivative at $558 \mathrm{~nm}$ from DESIS compared with midday GPP from flux towers. Point colors are described in Fig. 3 caption.

The first derivative at $734 \mathrm{~nm}$, in the red edge, also has a high correlation with midday GPP (Fig. 7), however there are issues with this index. The correlation is driven by widely separated groups of points from the conifer and deciduous sites, while the deciduous winter observations have high residuals (Fig. 9).

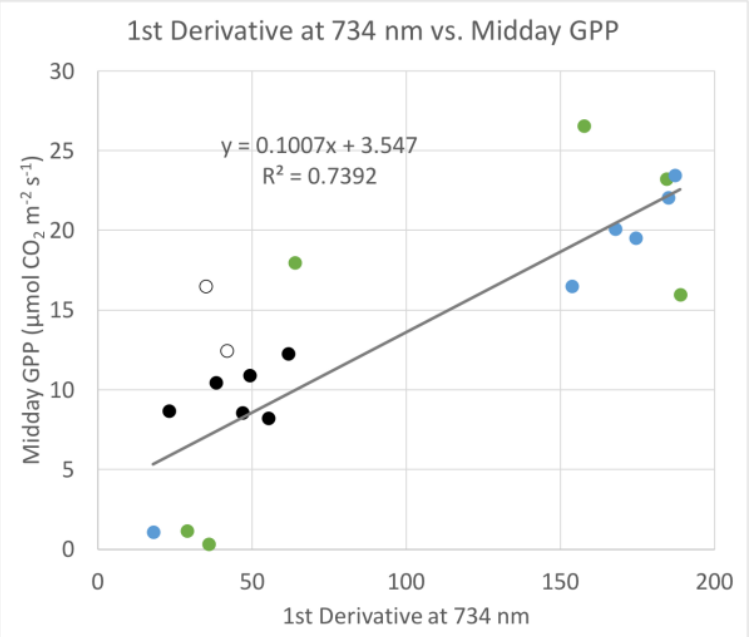

Figure 9. First derivative at $734 \mathrm{~nm}$ from DESIS compared with midday GPP from flux towers. Point colors are described in Fig. 3 caption.

Choosing the maximum first derivative does not improve retrieval of midday GPP, with a $\mathrm{R}^{2}$ of 0.62 and a distribution of points similar to the derivative at $734 \mathrm{~nm}$ shown in Fig. 9.

The depth of the continuum removed chlorophyll red absorption feature had a $\mathrm{R}^{2}$ poorer than NDVI alone $\left(\mathrm{R}^{2}=0.59\right)$. Also, like NDVI the feature depth showed little variation in the summer deciduous site observations.

\subsection{Partial Least Squares Regression}

PLSR is able to make use of information from all of the available spectral bands and performed very well when applied to these data including the US-xWR snow observations (Fig. 10). The weightings of the derived coefficients point out the importance of the red edge around $715 \mathrm{~nm}$ and the edge of the water absorption feature at $945 \mathrm{~nm}$ (Fig. 11). The general applicability of these coefficients must be tested against independent observations, but the results suggest the potential usefulness of PLSR to retrieve GPP.

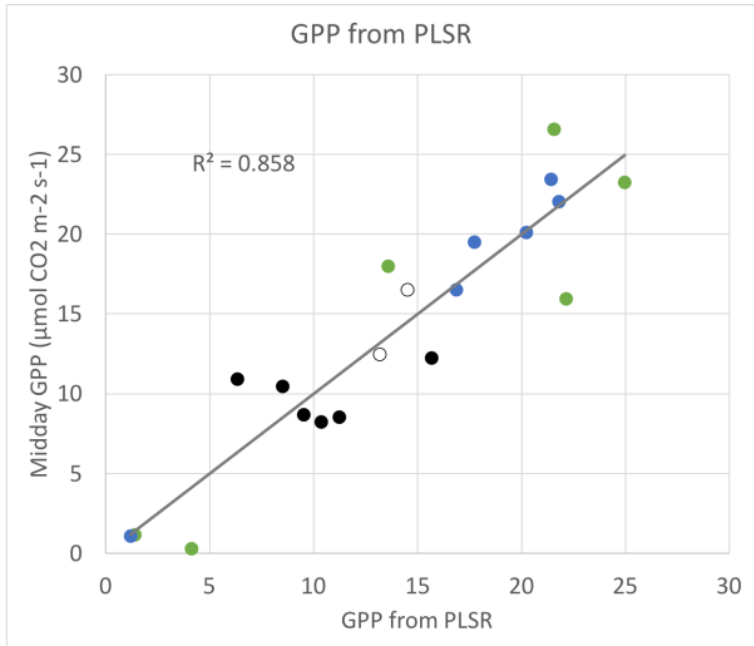

Figure 10. PLSR using DESIS reflectances compared with midday GPP. Point colors are described in Fig. 3 caption. 


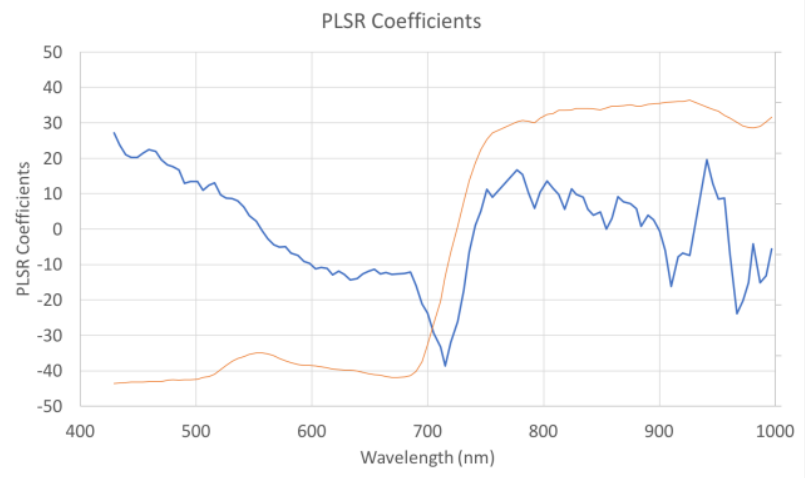

Figure 11. PLSR coefficients using DESIS reflectances applied to midday GPP from flux towers. Blue line shows the coefficient values, orange line is a representative reflectance spectra (not scaled to y-axis) for orientation.

\section{CONCLUSIONS}

This work demonstrates the potential of spectral information to improve descriptions and monitoring of ecosystem productivity across widely distributed sites with different forest types, through the seasons and across years. There are multiple promising approaches that make use of the spectral information available in the hyperspectral DESIS imagery that are not presently available from multispectral imagers, such as Landsat OLI or MODIS. Successful approaches included spectral vegetation indices, spectral derivatives, and partial least squares regressions. The increased information content available from more spectral bands and continuous spectra improves the capacity to describe productivity. Testing algorithms using multi-site and time observations illustrates the robustness of the approaches providing some confidence that these methods can be applied across images to map spatial patterns of forest productivity and track productivity change over time, in areas away from flux towers. This leads to advances in forest management capabilities and ecosystem science. Further, these algorithms may be applied to future orbital imaging spectrometers, such as the planned Plankton, Aerosol, Cloud, ocean Ecosystem (PACE), Surface Biology and Geology (SBG), and Copernicus Hyperspectral Imaging Mission (CHIME) missions.

\section{ACKNOWLEDGEMENTS}

The National Ecological Observatory Network is a program sponsored by the National Science Foundation and operated under cooperative agreement by Battelle. This material is based in part upon work supported by the National Science Foundation through the NEON Program.

Operation of the US-Ha1 site is supported by the AmeriFlux Management Project with funding by the U.S. Department of Energy's Office of Science under Contract No. DE-AC0205CH11231, and additionally is a part of the Harvard Forest LTER site supported by the National Science Foundation (DEB1832210).

This work is funded through NASA's Science Mission Directorate's Earth Science Division Commercial SmallSat Data Analysis program NNH20ZDA001N-CSDA.

\section{REFERENCES}

Amiro, B. D. et al., 2006. Carbon, energy and water fluxes at mature and disturbed forest sites, Saskatchewan, Canada. Agricultural and Forest Meteorology, 136(3-4), 237-251.

Asner, G.P., Martin, R.E., Anderson, C.B., Knapp, D.E., 2015. Quantifying forest canopy traits: Imaging spectroscopy versus field survey. Remote Sensing of Environment, 158, 15-27.

Campbell, P.K.E. et al., 2013. EO-1 Hyperion reflectance time series at calibration and validation sites: Stability and sensitivity to seasonal dynamics. IEEE J. Sel. Topics Appl. Earth Obs. Remote Sens. 6(2), 276-290.

DESIS ATBD, 2015: DESIS ATBD L1A, L1B, L1C, L2A Processors. Doc. ID PAV-DLR-TN-004, Issue 1.3, 1-85, Date 2015-07-204.

Gitelson, A. 2011: Nondestructive estimation of foliar pigment (chlorophylls, carotenoids, and anthocyanins) contents: Evaluating a semianalytical three band model, in Hyperspectral Remote Sensing of Vegetation, P. S. Thenkabail, J. G. Lyon, and A. Huete, Eds. CRC Press.

Grace, J., Nichol, C., Disney, M., Lewis, P., Quaife, T., Bowyer, P., 2007. Can we measure terrestrial photosynthesis from space directly, using spectral reflectance and fluorescence?. Global Change Biology, 13(7), 1484-1497.

Hall, F.G., Huemmrich, K.F., Goward, S.N., 1990. Use of narrow-band spectra to estimate the fraction of absorbed photosynthetically active radiation. Remote Sensing of Environment, 32(1), 47-54.

Huemmrich, K.F., Campbell, P.K.E., Gao, B.C., Flanagan, L.B., Goulden, M., 2017. ISS as a platform for optical remote sensing of ecosystem carbon fluxes: a case study using HICO. IEEE Journal of Selected Topics in Applied Earth Observations and Remote Sensing, 10(10), 4360-4375.

Huemmrich, K. F., Campbell, P., Landis, D., Middleton, E., 2019. Developing a common globally applicable method for optical remote sensing of ecosystem light use efficiency. Remote Sensing of Environment, 230, 111190.

Kokaly, R.F., 2011. PRISM: Processing routines in IDL for spectroscopic measurements (installation manual and user's guide, version 1.0), U.S. Geological Survey Open-File Report 2011b1155, http://pubs.usgs.gov/of/2011/1155/

Monteith, J.L., 1977. Climate and efficiency of crop production in Britain. Philosoph. Trans. Roy. Soc. London B, Biol. Sci. 281(980), 277-294.

Peng, Y., Gitelson, A.A., 2011. Application of chlorophyllrelated vegetation indices for remote estimation of maize productivity. Agricultural and Forest Meteorology, 151(9), 1267-1276.

Reichstein, M. et al., 2005. On the separation of net ecosystem exchange into assimilation and ecosystem respiration: review and improved algorithm. Global Change Biology, 11(9), 1424-1439.

Roberts, D.A., Roth, K.L., Perroy, R.L., 2011: Hyperspectral vegetation indices, in Hyperspectral Remote Sensing of 
Vegetation, P. S. Thenkabail, J. G. Lyon, and A. Huete, Eds. CRC Press.

Russell, G., Jarvis, P.G., Monteith, J.L., 1989: Absorption of radiation by canopies and stand growth, in Plant Canopies: Their Growth, Form and Function, G. Russell, B. Marshall, and P. G. Jarvis, Eds. Cambridge Univ. Press.

S. P. Serbin et al., 2015. Remotely estimating photosynthetic capacity, and its response to temperature, in vegetation canopies using imaging spectroscopy. Remote Sensing of Environment, $167,78-87$.

Savitzky, A., Golay, M. J., 1964. Smoothing and differentiation of data by simplified least squares procedures. Analytical Chemistry, 36(8), 1627-1639.

Urbanski, S., Barford, C., Wofsy, S., Kucharik, C., Pyle, E., Budney, J., McKain, K., Fitzjarrald, D., Czikowsky, M., Munger, J. W., 2007. Factors controlling CO2 exchange on timescales from hourly to decadal at Harvard Forest. Journal of Geophysical Research, 112:G2.

Ustin, S. L., Gitelson, A. A., Jacquemoud, S., Schaepman, M., Asner, G. P., Gamon, J. A., Zarco-Tejada, P., 2009. Retrieval of foliar information about plant pigment systems from high resolution spectroscopy. Remote Sensing of Environment, 113, S67-S77. 